\section{FORMAÇÃO PROFISSIONAL DO GESTOR ESPORTIVO PARA O MERCADO DE TRABALHO: A (IN)FORMAÇÃO DOS CURSOS DE BACHARELADO EM EDUCAÇÃO FÍSICA DO BRASIL}

\author{
SPORTS MANAGERS' PROFESSIONAL TRAINING FOR THE LABOR MARKET: \\ THE (IN)FORMATION OF PHYSICAL EDUCATION SCHOOLS IN BRAZIL
}

FORMACIÓN PROFESIONAL DEL GESTOR DEPORTIVO PARA EL MERCADO DE TRABAJO: LA (IN)FORMACIÓN DE LOS CURSOS DE LICENCIATURA EN EDUCACIÓN FÍSICA DE BRASIL

\author{
Ricardo Teixeira Quinaud*, Gelcemar Oliveira Farias*, \\ Juarez Vieira Nascimento*
}

Palavras chave: Universidades. Educação Física e Treinamento. Gestão.

Currículo.

Keywords:

Universities. Physical Education and Training. Management. Curriculum.

Palabras clave: Universidades. Educación Física y Entrenamiento. Gestión.

Currículo.
Resumo: 0 objetivo deste estudo documental, com abordagem quantiqualitativa, foi analisar a oferta de disciplinas na área de Gestão Esportiva nas estruturas curriculares dos cursos de bacharelado em Educação Física de universidades públicas brasileiras (federais e estaduais). As evidências encontradas revelaram o predomínio da oferta de até duas disciplinas nesta área, cujas temáticas concentram-se em Administração e Marketing Esportivo e Gestão de Políticas Públicas em Saúde, Esporte e Lazer. A ampliação da oferta de eixo curricular específico, com realização de estágio curricular, é recomendada para melhor atender as demandas formativas e profissionais na área de Gestão Esportiva.

\begin{abstract}
This quantitative and qualitative documental study looked into the offer of Sports Management courses in Physical Education schools' curricula at Brazilian - federal and state - public universities. The evidence found showed the offer of up to two disciplines in the area, whose topics focus on Sports Administration and Marketing, and Management of Health, Sports and Leisure Policies. Expanding the offer of specific curricular contents including practicum is recommended to better meet the training and professional demands in Sports Management area.
\end{abstract}

Resumen: El objetivo de este estudio documental, con abordaje cuantitativo y cualitativo, fue analizar la oferta de disciplinas en el área de Gestión Deportiva en las estructuras curriculares de los cursos de licenciatura en Educación Física de universidades públicas brasileñas (federales y estatales). Las evidencias encontradas revelaron el predominio de la oferta de hasta dos disciplinas en el área, cuyas temáticas se concentran en Administración y Marketing Deportivo y Gestión de Políticas Públicas en Salud, Deporte y Ocio. La ampliación de la oferta de eje curricular específico, con realización de práctica curricular, es recomendada para atender mejor las demandas formativas y profesionales en el área de Gestión Deportiva.
*Universidade Federal de Santa Catarina. Florianópolis, SC, Brasil. E-mail: ricardoquinaud@gmail.com; fariasgel@hotmai.com; juarez.nascimento@ufsc.br.

Recebido em: 08-08-2017 Aprovado em: 01-02-2018

DOI: https://doi.org/10.22456/1982-8918.75557 (c) (i) () Licence 


\section{INTRODUÇÃO}

No cenário da intervenção profissional em Educação Física, distintos postos de trabalho são ocupados pelos profissionais, os quais exigem o domínio de determinadas competências e de conhecimentos específicos (NASCIMENTO, 2002; 2006). Na última década, a formação inicial e a intervenção profissional em Educação Física têm despertado o interesse de diversos pesquisadores, independentemente do espaço e do tempo de atuação (BEZERRA et al., 2014; BRASIL et al., 2016; CARDOSO; BATISTA; GRAÇA, 2016; FARIAS et al., 2016; INÁCIO; MORAES; SILVEIRA, 2013; MILISTETD et al., 2015; ROSSI; MUNSTER, 2013; SAAD; REZER; REZER, 2010). Entretanto, o cenário científico ainda carece de estudos a respeito da gestão esportiva na formação inicial (BASTOS, 2003), de modo a propiciar a inserção do profissional de Educação Física como um gestor esportivo, ampliando e consolidando os espaços de intervenção e redimensionando as estratégias de ação.

O gestor esportivo, enquanto um dos responsáveis pelo desenvolvimento do esporte, tem assumido importante papel na gestão de recursos humanos e do mercado de negócios, favorecendo também a promoção de associações representativas (ROCHA; BASTOS, 2011; VIEIRA; STUCCHI, 2007). Assim, a ampliação e a melhoria da qualidade da formação inicial desses profissionais são necessárias, no intuito de que a gestão do esporte deixe de ser amadora e passe a profissionalizar-se (MAZZEI et al., 2012; MOCSÁNYI; BASTOS, 2005; ROCHA; BASTOS, 2011).

Ao ser reconhecida como uma das áreas de intervenção do profissional de Educação Física (CONSELHO FEDERAL DE EDUCAÇÃO FÍSICA, 2002), a formação inicial de gestores esportivos ocorre nos cursos de bacharelado em Educação Física (CÁRDENAS; FEUERSCHUTTE, 2015) e aos poucos tem ganhado mais espaço nos currículos universitários (MONTAGNER; SCAGILIA; AMAYA, 2012). Além de oportunizarem aos estudantes importantes aprendizagens sobre o real funcionamento do mundo profissional, ainda no tempo da formação universitária (HAAN; SHERRY, 2012; JACKOWSKI; GULLION, 1998; JONES; JONES, 2014), as estruturas curriculares contemplam os saberes do gestor esportivo por meio de disciplinas cujas temáticas estão relacionadas à gestão e à políticas do esporte (MAZZEl; AMAYA, BASTOS, 2013).

Embora as resoluções 07/2004 (BRASIL, 2004) e 04/2009 (BRASIL, 2009) compreendam importantes marcos regulatórios brasileiros dos cursos de graduação em Educação Física, as dimensões da formação inicial do gestor esportivo e as competências a serem adquiridas no decorrer do curso não são priorizadas, diante da perspectiva de formação generalista na área. De fato, as estruturas curriculares necessitam contemplar disciplinas e estágios obrigatórios que abordem o desenvolvimento de competências e o saber do gestor esportivo (FEITOSA; NASCIMENTO, 2006; ROCHA; BASTOS, 2011) para proporcionar o desenvolvimento da profissionalização do gestor (AZEVÊDO; BARROS; SUAIDEN, 2004; BASTOS, 2003; BASTOS et al., 2006; VALENTE; SERAFIM, 2006). Assim, este estudo tem por objetivo analisar a oferta de disciplinas na área de Gestão Esportiva nas estruturas curriculares dos cursos de bacharelado em Educação Física de universidades públicas brasileiras (federais e estaduais). 


\section{PROCEDIMENTOS METODOLÓGICOS}

A investigação foi caracterizada como descritiva, com abordagem quantiqualitativa dos dados a partir do delineamento documental (DELGADO; MARIN; SÁNCHEZ, 2011). Enquanto que a abordagem quantitativa foi utilizada na sistematização dos resultados numéricos, a abordagem qualitativa foi empregada devido à seleção, à focalização e à transformação dos dados em informações organizadas de acordo com as temáticas (GIL, 2008).

A coleta de dados ocorreu no website do governo federal (emec.mec.gov.br) no dia 6 de julho de 2016. A ferramenta no website do governo federal permite a busca precisa e detalhada de todas as instituições de ensino superior, assim como os cursos cadastrados e reconhecidos no Sistema Nacional de Ensino Superior (SINAES). Na busca avançada das informações foram selecionadas, inicialmente, as opções instituição de ensino superior, pública federal e, posteriormente, pública estadual, universidade e situação ativa, respectivamente.

A ferramenta de busca ainda apresenta a opção para selecionar todos os cursos oferecidos pela instituição universitária, clicando na opção graduação. Neste estudo foram selecionadas apenas aquelas instituições que possuíam o curso de bacharelado em Educação Física. Após esta primeira etapa, todos os websites das universidades que apresentavam 0 curso de bacharelado em Educação Física foram consultados, no intuito de verificar a oferta ou não de disciplinas relacionadas a gestão esportiva.

As orientações de Sparkes e Smith (2014) para realização de pesquisas qualitativas foram empregadas, nomeadamente a imersão e procura por temas, a identificação e nomeação dos temas, a conexão e organização dos temas, a verificação cruzada e confirmação. Além disso, o software Nvivo versão 9.2 foi utilizado, considerando que este recurso se tornou uma ferramenta poderosa em investigações qualitativas, pois auxilia a desvendar diferentes contextos e relaciona distintas informações, ao mesmo tempo em que se faz uso de análises temáticas com maior profundidade das explanações (GRBICH, 2013).

O agrupamento dos dados obtidos das ementas e das disciplinas permitiu a determinação da frequência relativa e percentual, cujos dados foram organizados na planilha de cálculo Excel, do sistema operacional Windows 10. O processo de análise de conteúdo (BARDIN, 2011) das disciplinas e das ementas encontradas nas universidades investigadas possibilitou a criação de seis categorias, nomeadamente Administração e Marketing Esportivo (funções administrativas na Educação Física; conceituação e utilização de diversas ferramentas do marketing; organograma, administração de pessoal e financeira; marketing aplicados ao esporte); Gestão de Políticas Públicas em Saúde, Esporte e Lazer (gestão das políticas da Educação Física, do esporte e do lazer; legislação e diretrizes voltadas para a orientação da Educação Física, do Lazer e do Esporte; legislação em saúde); Planejamento e Organização de Eventos (organização, congresso técnico e científico e cerimonial de eventos esportivos; regulamento e sistemas de disputa; organização e gerenciamento de competições esportivas); Gestão em Esporte, Saúde e Lazer (formação e equipe de profissionais de administração; gestão em academias, clubes, clínicas - contextos esportivos; gestão do mercado de trabalho em Educação Física); Empreendedorismo (inovação; fenômeno esportivo e relações com a sociedade; sistema educacional e empreendedorismo; oportunidades de negócios); Estágio Específico em Gestão Esportiva (estágio de prática profissional em Educação Física; estágio de práticas esportivas e gestão do esporte). Enquanto que a confirmação da representatividade 
das categorias (PATTON, 1990) foi estabelecida pela exaustividade na sua análise, a validade interpretativa (MAXWELL, 1992) obtida por meio do confronto e discussão de dois peritos com vasta experiência em pesquisa qualitativa e formação profissional em Educação Física.

\section{RESULTADOS}

A busca realizada ao website do governo federal resultou na identificação de 103 instituições de ensino superior, sendo $63(61,2 \%)$ universidades federais e 40 (38,8\%) universidades estaduais. Do total de instituições públicas selecionadas do Sistema Nacional de Ensino Superior, 76 ofertam cursos de Educação Física, sendo 46 o curso de bacharelado em Educação Física. Há 42 instituições de ensino superior que ofertam pelo menos uma disciplina na área de Gestão Esportiva, sendo 28 (66,7\%) universidades federais e 14 $(33,3 \%)$ universidades estaduais. Somente uma universidade federal não disponibilizou a grade curricular do curso de bacharelado em Educação Física. A consulta aos websites das universidades investigadas permitiu encontrar as ementas das disciplinas de 37 universidades (27 federais e dez estaduais) e foram disponibilizados os projetos político-pedagógicos de 34 universidades (29 federais e cinco estaduais).

A análise da distribuição geográfica dos cursos de bacharelado em Educação Física revelou que as regiões Sudeste (37,0\%), Sul (28,3\%) e Nordeste $(21,7 \%)$ são aquelas que concentram o maior número de cursos ofertados por universidades federais e estaduais (Tabela 1). A menor concentração foi observada nas universidades públicas das regiões Centro-Oeste $(6,5 \%)$ e Norte $(6,5 \%)$, sendo que nenhuma universidade estadual da Região Centro-Oeste oferta o curso de bacharelado em Educação Física ou o curso não estava cadastrado no website do governo federal na data pesquisada. Enquanto que a oferta de cursos de bacharelado em Educação Física por universidades federais é maior na Região Sudeste $(n=12)$, a oferta por universidades estaduais é maior na Região Sul $(n=7)$.

Tabela 1 - Número de cursos de bacharelado em Educação Física ofertados pelas universidades públicas por região brasileira.

\begin{tabular}{lccc}
\hline Região & $\begin{array}{c}\text { Universidades Federais } \\
(\mathbf{n}=31)\end{array}$ & $\begin{array}{c}\text { Universidades Estaduais } \\
(\mathbf{n}=15)\end{array}$ & $\begin{array}{c}\text { Total } \\
(\mathbf{n}=46)\end{array}$ \\
\hline Norte & $2(66,7 \%)$ & $1(33,3 \%)$ & 3 \\
Nordeste & $8(80,0 \%)$ & $2(20,0 \%)$ & 10 \\
Centro-Oeste & $3(100,0 \%)$ & - & 3 \\
Sudeste & $12(70,6 \%)$ & $5(29,4 \%)$ & 17 \\
Sul & $6(46,2 \%)$ & $7(53,8 \%)$ & 13 \\
\hline
\end{tabular}

Fonte: Dados da pesquisa.

Em relação aos currículos dos cursos de bacharelado em Educação Física que apresentavam disciplinas relacionadas a área da Gestão Esportiva, constatou-se o predomínio da oferta de uma $(35,7 \%)$ ou duas $(38,1 \%)$ disciplinas por curso nas universidades investigadas (Tabela 2). Poucos cursos $(4,8 \%)$ de universidades federais e estaduais ofertam cinco ou mais disciplinas. 
Tabela 2 - Número de disciplinas ofertadas no segmento da Gestão Esportiva nas estruturas curriculares das universidades federais e estaduais.

\begin{tabular}{lccc}
\hline Número de disciplinas & $\begin{array}{c}\text { Universidades Federais } \\
(\mathbf{n}=\mathbf{2 8})\end{array}$ & $\begin{array}{c}\text { Universidades Estaduais } \\
(\mathbf{n}=\mathbf{1 4})\end{array}$ & $\begin{array}{c}\text { Total } \\
(\mathbf{n}=42)\end{array}$ \\
\hline Uma disciplina & $11(73,3 \%)$ & $4(26,7 \%)$ & 15 \\
Duas disciplinas & $11(68,8 \%)$ & $5(31,3 \%)$ & 16 \\
Três disciplinas & $5(55,6 \%)$ & $4(44,4 \%)$ & 9 \\
Quatro disciplinas & - & - & 0 \\
Cinco disciplinas & $1(100 \%)$ & - & 1 \\
Seis disciplinas & - & $1(100 \%)$ & 1 \\
\hline
\end{tabular}

Fonte: Dados da pesquisa.

Ao considerar as categorias de análise referentes às disciplinas ofertadas (Tabela 3), nota-se que a maioria dos cursos de bacharelado em Educação Física investigados oferece disciplinas que abordam conteúdos de Administração e Marketing Esportivo (59,5\%) e Gestão de Políticas Públicas em Saúde, Esporte e Lazer (57,1\%). Nota-se também a oferta de disciplinas com conteúdos voltados ao Planejamento e Organização de Eventos (35,7\%) e à Gestão em Esporte, Saúde e Lazer (33,33\%).

Tabela 3 -Número de cursos que ofertam disciplinas da área de Gestão Esportiva de acordo com as categorias de análise.

\begin{tabular}{lccc}
\hline Categorias de Análise & $\begin{array}{c}\text { Universidades } \\
\text { Federais }(\mathbf{n = 2 8})\end{array}$ & $\begin{array}{c}\text { Universidades } \\
\text { Estaduais }(\mathbf{n = 1 4 )}\end{array}$ & $\begin{array}{c}\text { Total } \\
(\mathbf{n = 4 2})\end{array}$ \\
\hline Administração e Marketing Esportivo & $15(60,0 \%)$ & $10(40,0 \%)$ & 25 \\
Gestão de Políticas Públicas em Saúde, Esporte e Lazer & $14(58,3 \%)$ & $10(41,7 \%)$ & 24 \\
Planejamento e Organização de Eventos & $10(66,7 \%)$ & $5(33,3 \%)$ & 15 \\
Gestão em Esporte, Saúde e Lazer & $10(71,4 \%)$ & $4(28,6 \%)$ & 14 \\
Empreendedorismo & $3(50,0 \%)$ & $3(50,0 \%)$ & 6 \\
Estágio Curricular em Gestão Esportiva & $1(50,0 \%)$ & $1(50,0 \%)$ & 2 \\
\hline
\end{tabular}

Fonte: Dados da pesquisa.

O empreendedorismo (14,3\%) e o Estágio Curricular em Gestão Esportiva (4,8\%) são disciplinas menos frequentes nos cursos de bacharelado em Educação Física. Além disso, a análise pormenorizada dos créditos ofertados revelou que as disciplinas são predominantemente de natureza teórica, com poucas oportunidades proporcionadas aos estudantes para colocarem em prática seus conhecimentos, como os estágios curriculares.

Considerando que um eixo curricular compreende a oferta de três ou mais disciplinas em determinado segmento curricular, inclusive com a oferta de estágio curricular quando o eixo é de orientação para intervenção profissional, poucos cursos investigados de universidades federais $(n=6)$ e estaduais $(n=5)$ apresentam indícios da presença de um eixo curricular na área de Gestão Esportiva. A análise da periodização da oferta de disciplinas na estrutura curricular dos cursos que possuem pelo menos três disciplinas na área de Gestão Esportiva (Tabela 4) revelou que a estrutura curricular de somente seis cursos investigados pode configurar um eixo curricular em Gestão Esportiva. As demais estruturas curriculares contemplam até duas disciplinas nesta área ou concentram a oferta de disciplinas em duas categorias de análise. 
Tabela 4 - Distribuição da oferta de disciplinas nas categorias de análise nas estruturas curriculares das universidades que contemplam três ou mais disciplinas na área de gestão esportiva.

\begin{tabular}{|c|c|c|c|c|c|c|}
\hline & $\begin{array}{l}\text { Gestão de } \\
\text { Políticas } \\
\text { Públicas em } \\
\text { Saúde, Esporte } \\
\text { e Lazer }\end{array}$ & $\begin{array}{c}\text { Administração } \\
\text { e Marketing } \\
\text { Esportivo }\end{array}$ & $\begin{array}{c}\text { Planejamento } \\
\text { e Organização } \\
\text { de Eventos }\end{array}$ & $\begin{array}{c}\text { Gestão em } \\
\text { Esporte, } \\
\text { Saúde e } \\
\text { Lazer }\end{array}$ & Empreendedorismo & $\begin{array}{c}\text { Estágio } \\
\text { Curricular } \\
\text { em Gestão } \\
\text { Esportiva }\end{array}$ \\
\hline UE A & 1 & 1 & 1 & 1 & 1 & 1 \\
\hline UF A & 1 & 1 & 1 & 1 & 1 & \\
\hline UE B & 1 & & 1 & & 1 & \\
\hline UE C & 1 & 1 & 1 & & & \\
\hline UED & 1 & 1 & & 1 & & \\
\hline UF B & & & 1 & 1 & & 1 \\
\hline UF C ${ }^{*}$ & & 2 & & 1 & & \\
\hline UF D* & 1 & & & 2 & & \\
\hline $\mathrm{UFE}^{*}$ & & 2 & & & 1 & \\
\hline $\mathrm{UFE}^{*}$ & 1 & 2 & & & & \\
\hline UE F $F^{*}$ & 1 & 2 & & & & \\
\hline
\end{tabular}

Fonte: Dados da pesquisa.

*Universidades que apresentam mais de uma disciplina inserida na mesma categoria de análise. UE: Universidade Estadual; UF: Universidade Federal

Um aspecto a destacar é que somente duas universidades investigadas contemplam a formação específica de profissionais de Educação Física para atuar no segmento da gestão esportiva, expressando a intencionalidade no projeto político-pedagógico do curso, nomeadamente no perfil profissional, nos objetivos geral e específicos e na estrutura curricular.

\section{DISCUSSÃo}

A expansão da oferta de cursos de educação superior no cenário brasileiro (BARROS, 2015) tem revelado também a evolução das matrículas na rede pública (BRASIL, 2014), bem como o crescimento e a procura por cursos de bacharelado (BRASIL, 2012). A distribuição desequilibrada dos cursos de Educação Física nas regiões geográficas no Brasil, observada no período de 1991 a 2004 (HUNGER et al., 2006), parece permanecer na atualidade, porque a oferta de cursos de bacharelado por instituições públicas federais e estaduais concentra-se nas regiões Sudeste, Sul e Nordeste.

A preocupação com a melhoria da qualidade da formação de profissionais na área de Gestão Esportiva é justificada pelo aumento da sua demanda (SKINNER; GILBERT, 2007) e pela necessidade de contratação de pessoas qualificadas para a sobrevivência da gestão esportiva futura (SCHWAB et al., 2015). Além de adquirir competências em ambientes institucionalizados de aprendizagem (JOAQUIM; BATISTA; CARVALHO, 2011), o profissional deve ser um profundo conhecedor do ambiente em que atua, aumentando a credibilidade e as possibilidades de intervenção profissional no Brasil (MAZZEl et al., 2012). No entanto, a adequação curricular às necessidades formativas e profissionais na área da Gestão Esportiva não é uma tarefa fácil, sendo necessária a análise inicial do ambiente de atuação do profissional (DESENSI et al., 1990) e a sistematização de grupo de profissionais e pesquisadores engajados na ressignificação da própria intervenção profissional. 
Ao considerar o campo da gestão do esporte no Brasil, acredita-se que a área ainda se encontra em busca de sua afirmação, reconhecimento e importância (MAZZEl; ROCCO JÚNIOR, 2017). Apesar das lacunas existentes nas matrizes curriculares dos cursos (MAZZEl; AMAYA; BASTOS, 2013), a gestão do esporte está alcançando maturidade e respeito no meio acadêmico (ROCHA; BASTOS, 2011) e talvez, mesmo de forma prematura, tem aumentado gradativamente o seu poder nos currículos.

A partir da Resolução 07/CNE/2004 (BRASIL, 2004), os currículos dos cursos de bacharelado procuraram ampliar o leque de contextos de intervenção profissional em Educação Física, de modo a atender às demandas crescentes do mercado de trabalho, bem como estreitar a relação entre a gestão esportiva, Educação Física e universidade. Assim, para atender às novas demandas formativas foi necessário alterar também o perfil do egresso do curso de bacharelado em Educação Física, estabelecendo competências, habilidades e atitudes a serem fomentadas no decorrer da integralização do curso.

A aglutinação de diferentes temáticas da gestão esportiva em uma única disciplina (CARDENAS; FEUERSCHUTTE, 2015) compreende uma importante evidência de sua legitimação na formação inicial em Educação Física. Entretanto, ao ressaltar a baixa oferta de disciplinas de gestão, não se limita a pensar que a maior oferta de disciplinas legitimaria esta área nos currículos e nem tampouco que a gestão esportiva seria a mais importante para Educação Física. De fato, o contexto da gestão não está inserido somente no viés administrativo, mas está presente e atuante nos contextos pedagógicos e do treinamento, em organizações e manifestações esportivas, bem como nas próprias instituições de ensino superior (MAZZEl; ROCCO JÚNIOR, 2017).

Embora a inserção de conhecimentos sobre gestão esportiva nos currículos universitários tenha sido mais contemplada em disciplinas, é notória a necessidade de sua fundamentação nos estágios supervisionados e nas atividades complementares, redimensionando o olhar para a formação do bacharel. Além disso, um fator que gera preocupação é a carência de estudos que abordam os estágios nos cursos de bacharelado em Educação Física, os quais permanecem situados no campo da legislação (RINALDI; PIZZANI, 2012; SILVA; SOUZA, CHECA, 2010;), enquanto que a demanda de investigações que tratam das atividades complementares é bastante restrita.

As disciplinas de Administração e Marketing Esportivo são ofertadas com maior frequência nos currículos dos cursos de graduação em Educação Física, devido especialmente à espetacularização esportiva, que se transformou em um mecanismo essencial para a valorização da "marca" do esporte em que se está atuando (VLASTUIN; ALMEIDA; MARCHI JÚNIOR, 2008). Além disso, destaca-se o esporte contemporâneo como um objeto mercadológico potencializado por meio de suas inúmeras formas de manifestação (MARQUES; GUTIERREZ; MONTAGNER, 2009).

A importância atribuída à temática de Gestão de Políticas Públicas em Saúde, Esporte e Lazer demonstra a preocupação com a estruturação de políticas que possam reunir e guiar contextos particulares, como econômico, político, social e processos do esporte (MCCREE, 2009), assinalando também que a participação é imprescindível na construção das políticas do esporte (SAM; JACKSON, 2004). Ressalta-se que a qualidade e a importância destinada à temática refletirão na própria qualidade das políticas e na solução de seus problemas (DONALDSON; LEGGETT; FINCH, 2011). 
O Planejamento e Organização de Eventos e a Gestão em Esporte, Saúde e Lazer são disciplinas pouco contempladas nos cursos investigados, o que revela determinada preocupação em instruírem seus estudantes, em relação a diferentes temáticas, para estarem qualificados para intervenção profissional futura (DESENSI et al., 1990). Além disso, tais categorias podem contribuir de forma reflexiva e de forma crítica para novas perspectivas culturais (SHERRY; SCHULENKORF; CHALIP, 2015), de modo a ajudar no entendimento das particularidades da gestão esportiva (HAAN; SHERRY, 2012).

Apesar do estágio curricular providenciar o engajamento do estudante no mercado de trabalho, criar oportunidades de relacionamentos profissionais e atualizar o estudante sobre as necessidades do mercado profissional (BRAUNSTEI-MINKOVE; DELUCA, 2015; JACKOWSKI; GULLION, 1998; SURUJLAL; SINGH, 2010;), a realização de estágio curricular com foco específico em Gestão Esportiva é ainda bastante escassa nas instituições públicas investigadas. Esta situação difere do estudo realizado com universidades privadas de São Paulo, no qual Silva, Souza e Checa (2010) encontraram a realização frequente de projetos de gestão nos tempos de estágios.

Uma evidência preocupante do estudo é a presença de um eixo curricular em Gestão Esportiva em somente seis cursos investigados, sendo que apenas dois cursos contemplam a formação específica nesta área nos respectivos projetos político-pedagógicos. A frágil abordagem temática nesta área em cursos de bacharelado em Educação Física pode justificar a baixa procura de recém-formados para atuar na Gestão Esportiva (MONTAGNER; SCAGLIA; AMAYA, 2012). Assim, a criação de eixo curricular nesta área é recomendável para favorecer ao estudante a aquisição de conhecimentos a serem aplicados nos específicos contextos da gestão (DESENSI et al., 1990), o domínio de habilidades primordiais ao seu futuro profissional (AZEVÊDO; BARROS; SUAIDEN, 2004; BASTOS et al., 2006; MACIEL, 2009) e o alinhamento necessário às dinâmicas demandas do mercado de trabalho (BRAUNSTEI-MINKOVE; DELUCA, 2015). Destaca-se também o importante papel do profissional da gestão esportiva em potencializar as habilidades dos estudantes para realizarem conexões de informações e ideias para o aprimoramento da gestão (ZAKUS; MALLOY; EDWARDS, 2007), bem como participarem e contribuírem com a sociedade (SCHWAB et al., 2013).

\section{CONSIDERAÇÕES FINAIS}

As evidências encontradas no estudo permitiram concluir que a oferta de disciplinas na área de Gestão Esportiva, nas grades curriculares dos cursos de bacharelado em Educação Física, compreende uma importante iniciativa para assegurar a intervenção do futuro profissional neste setor. Todavia, é preocupante o número reduzido de cursos que oportunizam a oferta de disciplinas desta natureza na formação de bacharéis em Educação Física, bem como a concentração da oferta por instituições públicas federais e estaduais localizadas nas regiões Sudeste, Sul e Nordeste.

Embora se perceba a preocupação de professores inseridos nas universidades brasileiras em formar profissionais capazes de realizar atividades de administração e marketing e com pensamentos críticos a respeito da gestão de políticas públicas em saúde, esporte e lazer, os dados do estudo indicam que este movimento nas instituições de ensino superior ainda é tímido. Ressalta-se que o Planejamento e Organização de Eventos e a Gestão em 
Esporte, Saúde e Lazer são disciplinas pouco contempladas nos cursos investigados, assim como a realização de estágio curricular com foco específico em Gestão Esportiva.

A ampliação da oferta de eixo curricular específico, com mais disciplinas e realização de estágio curricular obrigatório, é recomendada para melhor atender as demandas formativas e profissionais na área de Gestão Esportiva. Por fim, as universidades federais foram as que apresentaram maior oferta de cursos de bacharelados em Educação Física no Brasil, de disciplinas da área da gestão esportiva e superioridade ou equivalência de disciplinas considerando as categorias de análise. Não obstante, os estágios curriculares seguidos das disciplinas obrigatórias sobre o tema gestão devem ser contemplados nas matrizes curriculares, mediando a formação e a futura intervenção profissional.

Ainda que não tenha sido foco deste estudo, a extensão universitária pode ser uma das estratégias para dimensionar o conhecimento sobre a gestão esportiva. Finalmente, a ampliação da oferta de eixo curricular específico, com realização de estágio curricular, é recomendada para melhor atender as demandas formativas e os profissionais na área de Gestão Esportiva. Tal realização poderia ser uma iniciativa para qualificar a sua inserção no mercado de trabalho com uma demanda de saberes específicos e experiências práticas. A continuidade dos estudos também é sugerida para aprofundar as estratégias para dimensionar o conhecimento nas situações de aprendizagem, especialmente aquelas que buscam conciliar saberes específicos e experiências práticas, assim como maior proximidade da realidade da intervenção futura nesta área.

\section{REFERÊNCIAS}

AZEVÊDO, Paulo Henrique; BARROS, Jônatas de França; SUAIDEN, Samir. Caracterização do perfil do gestor esportivo dos clubes da primeira divisão de futebol do distrito federal e suas relações com a legislação esportiva brasileira. Revista da Educação Física, v.15, n 1, 33-42, jan./mar. 2004.

BARDIN, Laurence. Análise de conteúdo. Rio de Janeiro: Edições 70, 2011.

BARROS, Aparecida da Silva Xavier. Expansão da educação superior no Brasil: limites e possibilidades. Educação e Sociedade, v. 36, n. 131, p. 361-390, abr./jun. 2015.

BASTOS, Flavia Cunha et al. Perfil do administrador esportivo de clubes de São Paulo/Brasil. Revista Mackenzie de Educação Física e Esporte, v.5, n.1, p.13-22, jan./abr. 2006.

BASTOS, Flavia Cunha. Administração Esportiva: área de estudo, pesquisa e perspectivas no Brasil. Motrivivência, v.15, n.20/21, p.295-306, mar./dez. 2003.

BEZERRA, Liudmila de Andrade et al. Ginástica na formação inicial em educação física: análise das produções científicas. Revista da Educação Física, v. 25, n. 4, p. 663-673, jan./mar. 2014.

BRASIL, Vinicius Zeilmann et al. As ações pedagógicas para a intervenção do treinador de Surf.

Movimento, v. 22, n. 2, 403-416, abr./jun. 2016.

BRASIL. A democratização e expansão da educação superior no país 2003

- 2014, 2014. Disponível em: < http://portal.mec.gov.br/index.php?option=com 
docman\&view=download\&alias=16762-balanco-social-sesu-2003-2014\&ltemid=30192http://portal. mec.gov.br/index.php?option=com docman\&view=download\&alias=16762-balanco-social-sesu-20032014\&ltemid=30192 >. Acesso em: 07 ago. 2017.

BRASIL. Censo da Educação Superior 2012, 2012. Disponível em: <http://portal.mec. gov.br/index.php?option=com docman\&view=download\&alias=14153-coletiva-censo-superior2012\&ltemid=30192>. Acesso em: 07 ago. 2017.

BRASIL. Resolução n. 4, de 6 de abril de 2009. Dispõe sobre carga horária mínima e procedimentos relativos à integralização e duração dos cursos de graduação em Biomedicina, Ciências Biológicas, Educação Física, Enfermagem, Farmácia, Fisioterapia, Fonoaudiologia, Nutrição e Terapia Ocupacional, bacharelados, na modalidade presencial. Diário Oficial da União, Brasília, 7 de abril de 2009. Disponível em: http://portal.mec.gov.br/dmdocuments/ rces004 09.pdf. Acesso em: 07 ago. 2017.

BRASIL. Resolução n. 7, de 31 de março de 2004. Institui as Diretrizes Curriculares Nacionais para os cursos de graduação em Educação Física, em nível superior de graduação plena.

Diário Oficial da União, Brasília, 05 de abril de 2004. Disponível em: <http://portal.mec.gov.br/ cne/arquivos/pdf/ces0704edfisica.pdf>. Acesso em: 07 ago. 2017.

BRAUNSTEI-MINKOVE, Jessica; DELUCA, Jaime. Effectively Adapting the Sport Management Curricula. Schole: A Journal of Leisure Studies and Recreation Education, v. 30, n. 2, p. 12-30, jan. 2015.

CÁRDENAS, Alfredo Ribeiro; REUERSCHUTTE, Simone Ghisi. A gestão na formação inicial em educação física: um olhar qualitativo sobre currículos, disciplinas e ementas dos cursos de bacharelado de Santa Catarina. Revista do Programa de Pós-Graduação- UNESC, v. 4, n. 1 , p. 10-26, jan./jun. 2015.

CARDOSO, Inês; BATISTA; Paula; GRAÇA, Amândio. A identidade do professor de Educação Física: um processo simultaneamente biográfico e relacional. Movimento, v. 22, n. 2, p. 523538, abr./jun. de 2016.

CONFEF. Resolução n. 46, de 18 de fevereiro de 2002. Dispõe sobre a Intervenção do Profissional de Educação Física e respectivas competências e define os seus campos de atuação profissional. Rio de Janeiro, 18 de fevereiro de 2002. Disponível em: <http://www.confef. org.br/extra/resolucoes/conteudo.asp?cd resol=82>. Acesso em: 11 abr. 2017.

DELGADO, Sixto Cubo; MARÍN, Beatriz Martín; SANCHEZ, José Ramos. Métodos de investigación y análisis de datos em ciencisa sociales y de la salud. Madri: Pirámeide, 2011.

DESENSI, Joy et al. Sport Management Curricular Evaluation and Needs Assessment: a Multifaceted Approach. Journal of Sport Management, v. 4, n. 1, p. 31-58, jan. 1990.

DONALDSON, Alex; LEGGETT, Susan; FINCH, Caroline. Sports policy development and implementation in context: Researching and understanding the perceptions of community endusers. International Review for the Sociology of Sport, v.47, n, 6, p. 743- 760, sep. 2011.

FARIAS, Gelcemar Oliveira et al. Formação Inicial em Educação Física e a Intervenção Profissional no Segmento das Atividades de Aventura. In: FUMES, Neiza de Lourdes Frederico et al. (Org.). Educação Física, Desporto e Lazer: perspectivas luso-brasileiras. Maceió: EDUFAL, 2016.v. 4, p. 37-53. 
FEITOSA, Wallacy Milton Nascimento; NASCIMENTO, Juarez Vieira. Educação Física: quais competências profissionais? In: SOUZA NETO, Samual; HUNGER, Dagmar. (Orgs.) Formação profissional em Educação Física: estudos e pesquisas. Rio Claro: Bioética, 2006. p. 87-108.

GIL, Antônio Carlos. Métodos e Técnicas de Pesquisa Social. 6. ed. São Paulo: Atlas, 2008.

GRBICH, Carol. Qualitative Data Analysis: an introduction. 2. ed. London: SAGE, 2013.

HAAN, Donna; SHERRY, Emma. Internationalization of the sport management curriculum: academic and student reflections. Journal of Studies in International Education, v. 16, n. 1, p. 24-39, jul. 2012.

HUNGER, Dagmar et al. Educação Física. In: HADDAD, Ana Estela, et al. A trajetória dos cursos de graduação na saúde: 1991-2004. Brasília: Inep/Mec, 2006. p. 87-139.

INÁCIO, Humberto Luís de Deus; MORAES, Thais Messias; SILVEIRA, Amanda Batista. Educação física e educação ambiental: refletindo sobre a formação e atuação docente. Revista da Faculdade de Educação Física da UNICAMP, v. 11, n. 4, p. 1-23, out./dez. 2013.

JACKOWSKI, Mick; GULLION, Laurie. Teaching sport management through service- learning: an undergraduate case study. National Association for Physical Education in Higher Education, v. 50, p. 251-265, abr. 1998.

JOAQUIM, Bárbara Andreia; BATISTA, Paula Maria; CARVALHO, Maria José. Revisão Sistemática sobre o perfil de competências do gestor desportivo. Movimento, v. 17, n. 1, p. 255, jan./mar. 2011.

JONES, Paul; JONES, Amanda. Attitudes of sports development and sports management undergraduate students towards entrepreneurship: a university perspective towards best practice. Education + Training, v. 56, n. 8/9, p. 716-73, 2014.

MACIEL, Marcos Gonçalves. Perfil do gestor de lazer em empresas. Revista Brasileira de Ciências do Esporte, v. 31, n. 1, p. 57-73, jan./mar. 2009.

MARQUES, Renato Francisco Rodrigues; GUTIERREZ, Gustavo Luis; MONTAGNER, Paulo César. Novas configurações socioeconômicas do esporte contemporâneo. Revista da Educação Física, v. 20, n. 4, p. 637-648, out./dez. 2009.

MAXWELL, Joseph. Understanding and validity in qualitative research. Harvard Educational Review, v. 62, n. 3, p. 279-301, 1992.

MAZZEI, Leandro Carlos et al. Centros de treinamento esportivo para o esporte de alto rendimento no Brasil: um estudo preliminar. Revista Mineira de Educação Física, Edição Especial, n. 1, p. 1575-1584, jan./mar. 2012.

MAZZEI, Leandro Carlos; AMAYA, Katherine; BASTOS, Flávia da Cunha. Programas acadêmicos de graduação em gestão do esporte no Brasil. Revista Mackenzie de Educação Física e Esporte, v. 12, n. 1, p. 219-234, 2013.

MAZZEI, Leandro Carlos; ROCCO JÚNIOR, Ary José. Um ensaio sobre a Gestão do Esporte: Um momento para a sua afirmação no Brasil. Revista de Gestão e Negócios do Esporte, v. 2, n. 1, p. 96-109, mai. 2017.

MCCREE, Roy. Sport policy and the new public management in the Caribbean: convergence or resurgence? Public Management Review, v.11, n. 4, p. 461-476, jul. 2009. 
MILISTETD, Michel et al. A aprendizagem profissional de treinadores esportivos: desafios da formação inicial universitária em Educação Física. Pensar a Prática, v. 18, p. 982-994, out./dec. 2015.

MOCSÁNYI, Vinícius; BASTOS, Flavia Cunha. Gestão de pessoas na administração esportiva: considerações sobre os principais processos. Revista Mackenzie de Educação Física e Esporte, v.4, n. 4, p. 55-69, out./dez. 2005.

MONTAGNER, Paulo Cesar; SCAGLIA, Alcides José; AMAYA, Katherine Grace. Desafios da formação em esporte para intervenção profissional no contexto da gestão: investigações iniciais. In: NASCIMENTO, Juarez Vieira; FARIAS, Gelcemar Oliveira. (Org.). Construção da identidade profissional em Educação Física: da formação à intervenção. Florianópolis: Ed. Da UDESC, 2012. p. 605-631.

NASCIMENTO, Juarez Vieira. Formação profissional em Educação Física: contextos de desenvolvimento curricular. Montes Claros: Ed. UNIMONTES, 2002.

NASCIMENTO, Juarez Vieira. Formação do profissional de Educação Física e novas diretrizes: reflexões sobre a reestruturação curricular. In: SOUZA NETO, Samuel; HUNGER, Dagmar. (Orgs.) Formação profissional em Educação Física: estudos e pesquisas. Rio Claro: Bioética, p. 59-76, 2006.

PATTON, Michael Quinn. Qualitative evaluation and research methods. 2. ed. Newbury Park: SAGE, 1990.

RINALDI, leda Parra Barbosa; PIZANI, Juliana. Desafios dos estágios nos currículos de bacharelado em Educação Física. In: NASCIMENTO, Juarez Vieira; FARIAS, Gelcemar Oliveira. (Org). Construção da identidade profissional em Educação Física: da formação à intervenção. Florianópolis: Ed. UDESC, 2012. p. 263-285.

ROCHA, Cláudio Miranda; BASTOS, Flávia da Cunha. Gestão do esporte: definindo a área. Revista Brasileira de Educação Física e Esporte, v. 25, n. esp, p. 91-103, dez. 2011.

ROSSI, Patrícia; MUSTER, Mey de Abreu van. Formação profissional em educação física adaptada: um estudo de caso. In: ENCONTRO DA ASSOCIAÇÃO BRASILEIRA DE PESQUISADORES EM EDUCAÇÃO ESPECIAL, 8, 2013. Anais do Congresso Brasileiro Multidisciplinar de Educação Especial. Londrina: UEL, 2013. v. 1. p. 1550-1561.

SAAD, Michel Angilli; REZER, Ricardo; REZER, Carla Reis. O ensino do esporte no processo de formação inicial em educação física. Revista Didática Sistêmica, edição especial v. 11, p.162178, 2010.

SAM, Michael; JACKSON, Steven. Sport policy development in New Zealand: paradoxes of an integrative paradigm. International Review for the Sociology of Sport, v. 39, n. 2, p. 205-222, jun. 2004.

SCHWAB, Keri A. et al. Career path in sport management. Journal of Leisure Studies Recreation Education, v. 30, n. 2, p. 1-11, Jan. 2015.

SCHWAB, Keri A. et al. Choosing sport management as a college major. Journal of Leisure Studies Recreation Education, v. 28, n. 2, p. 16-27, Jan. 2013.

SHERRY, Emmna; SCHULENKORF, Nico; CHAPIL, Laurence. Managing sport for social change: The state of play. Sport Management Review, v.18, n.1, p.1-5, fev. 2015. 
SILVA, Sheila Aparecida Pereira dos Santos; SOUZA, César Augusto Fernandes; CHECA, Felipe Marques. Situação do estágio supervisionado em IES privadas da grande São Paulo. Motriz, v.16, n.3, p.682-688, jul/set. 2010.

SKINNER, James; GILBERT, Keith. Sport management education: teaching and learning for the future. Sport Management Review, v. 10, p. 125-131, sep. 2007.

SPARKES, Andrew; SMITH, Brett. Qualitative research methods on Sports, Exercise and Health. London: Routledge, 2014.

SURUJLAL, Jhalukpreya; SINGH, Chunderpal. Internship as a mechanism for professional preparation of sport management personnel: an empirical study of students' perceptions. South African Journal for Research in Sport, Physical Education and Recreation, v. 32, n. 2, p. 117-130, 2010.

VALENTE, Rafael; SERAFIM, Maurício. Gestão esportiva: novos rumos para o futebol brasileiro. Revista de Administração de Empresas, v. 46, n. 3, p. 131-136, jul./set. 2006.

VIEIRA, Tiago Perez; STUCCHI, Sérgio. Relações preliminares entre a gestão esportiva e o profissional de Educação Física. Revista da Faculdade de Educação Física da UNICAMP, v. 5, n. 2, p. 113-128, jul./dez. 2007.

VLASTUIN, Juliana; ALMEIDA, Bárbara Schausteck; MARCHI JÚNIOR, Wanderley. O marketing esportivo na gestão do voleibol brasileiro: fragmentos teóricos referentes ao processo de espetacularização da modalidade. Revista Brasileira de Ciências do Esporte, v. 29, n. 3, p. 9-24, jul./set. 2008.

ZAKUS, Dwight; MALLOY, David Cruise; EDWARDS, Allan. Critical and ethical thinking in sport management: philosophical rationales and examples of methods. Sport Management Review, v. 10, p. 133-158, sep. 2007. 
